\title{
Lower fasting blood glucose in neurofibromatosis type 1
}

\author{
Aline Stangherlin Martins ${ }^{1}$, Ann Kristine Jansen ${ }^{2}$, Luiz Oswaldo \\ Carneiro Rodrigues ${ }^{1}$, Camila Maria Matos ${ }^{1}$, Marcio Leandro Ribeiro Souza', Juliana \\ Ferreira de Souza' ${ }^{1}$ Maria de Fátima Haueisen Sander Diniz ${ }^{3}$, Sandhi Maria Barreto ${ }^{4}$, \\ Leonardo Mauricio Diniz ${ }^{3}$, Nilton Alves de Rezende ${ }^{1,5}$ and Vincent Michael Riccardi ${ }^{6}$ \\ ${ }^{1}$ Neurofibromatosis Outpatient Reference Center, Federal University of Minas Gerais, Alameda Álvaro Celso 55, \\ Belo Horizonte, Minas Gerais, Brazil \\ ${ }^{2}$ Department of Nutrition, Federal University of Minas Gerais, Professor Alfredo Balena Avenue, 190, Santa Efigênia, \\ Belo Horizonte, Minas Gerais, Brazil \\ ${ }^{3}$ Department of Medical Clinic, Federal University of Minas Gerais, Professor Alfredo Balena Avenue, 190, \\ Santa Efigênia, Belo Horizonte, Minas Gerais, Brazil \\ ${ }^{4}$ Department of Preventive and Social Medicine, Federal University of Minas Gerais, Professor Alfredo Balena \\ Avenue, 190, Santa Efigênia, Belo Horizonte, Minas Gerais, Brazil \\ ${ }^{5}$ Department of Internal Medicine, Federal University of Minas Gerais, Professor Alfredo Balena Avenue, 190 \\ Santa Efigênia, Belo Horizonte, Minas Gerais, Brazil \\ ${ }^{6}$ The Neurofibromatosis Institute, 5415 Briggs Avenue, La Crescenta, CA, USA
}

\author{
Correspondence \\ should be addressed \\ to $\mathrm{N}$ A de Rezende \\ Email \\ narezende@terra.com.br
}

\begin{abstract}
Studies indicate a lower occurrence of diabetes mellitus (DM) in patients with neurofibromatosis type 1 (NF1). Fasting blood glucose (FBG) level is the main criterion used to diagnose DM and glucose intolerance. Therefore, this study compared FBG level between adults with NF1 and non-NF1 controls. We selected clinical records of 57 out of 701 individuals attending the Neurofibromatosis Outpatient Reference Center of the Clinics Hospital of the Federal University of Minas Gerais in Brazil. The selected patients with NF1 were matched to non-NF1 controls selected from the Brazilian Longitudinal Study of Adult Health according to sex, age (range, 35-74 years) and BMI at a ratio of 1:3. In both groups, individuals with DM were excluded. Median FBG level in the NF1 group $(86 \mathrm{mg} / \mathrm{dl}$ (range, 56-127 mg/dl)) was lower than that in the non-NF1 control group (102 mg/dl (range, $85-146 \mathrm{mg} / \mathrm{dl}))(P<0.001)$. Prevalence of FBG level $\geq 100 \mathrm{mg} / \mathrm{dl}$ in the NF1 group $(16 \%)$ was lower than that in the non-NF1 control group $(63 \%)(P<0.05)$. The chance of a high FBG level was $89 \%$ lower in the NF1 group (odds ratio, $0.112 ; 95 \% \mathrm{Cl}, 0.067-0.188$ ) $(P<0.05)$. In conclusion, adults with NF1 showed a lower FBG level and a lower prevalence of high FBG level compared with non-NF1 controls.
\end{abstract}

\section{Key Words}

- fasting blood glucose

- neurofibromatosis type 1

- type 2 diabetes mellitus

- insulin resistance

- nutritional status

\section{Introduction}

Neurofibromatosis type 1 (NF1) is an autosomal dominant genetic disease caused by an inherited or new mutation at the NF1 locus on the long arm of chromosome 17. This intragenic or whole-gene-deletion mutation results in dysfunction of the protein neurofibromin, which is involved in controlling growth and/or behavior of various tissues (1). NF1 is the most common human monogenetic disease, with a prevalence of approximately 1:3500 (2).

Clinical characteristics of NF1 include café au lait spots; cutaneous, subcutaneous, and plexiform

$$
\begin{aligned}
& \text { http://www.endocrineconnections.org } \\
& \begin{array}{lr}
\text { DOI: } 10.1530 / E C-15-0102 & 2016 \text { The authors }
\end{array}
\end{aligned}
$$


neurofibromas; axillary and/or inguinal freckling; Lisch nodules; intracranial gliomas; malignant peripheral nerve sheath tumors; and vascular and bone dysplasia $(3,4,5)$. The longevity of patients with NF1 is shorter than that of the general population (6). A 12-year study of 70 adult patients with NF1 found a decrease in life expectancy of approximately 15 years (7).

Although malignant tumors are the main cause of death in individuals with NF1 (7), the higher mortality rate also has been associated with other diseases, including atherosclerotic cardiovascular disease (ASCVD). Rasmussen et al. (6) evaluated the death certificates of 3770 individuals with NF1 in the USA from 1983 to 1997 and found that 658 deaths (17.4\%) were related to vascular disease (VD), whereas only 64 (1.7\%) were related to type 1 or type 2 diabetes mellitus (DM). Similarly, Masocco et al. (8) reviewed the death certificates of 632 individuals with NF1 in the USA from 1995 to 2006 and found that 101 deaths (16\%) were associated with VD, but only $2(0.3 \%)$ were related to DM. Madubata et al. (9) also reported a low frequency of DM-related medical claims among patients with NF1. In two studies of general population death certificates, Belfort and Oliveira (10) found that the DM-related mortality rate was from 3.97 to $4.41 \%$ in Brazil, while Rampatige et al. (11) found that such mortality rate was $10 \%$ in Sri Lanka.

VD refers to arterial and/or venous disorders in general, including developmental vascular dysplasia, ASCVD, and aneurysm. However, the specific type of VD in individuals with NF1 and its correlation with fasting blood glucose (FBG) level has not been investigated in previous studies $(6,8)$.

Both type 1 and type 2 DM contribute to development of VD (12). Type $1 \mathrm{DM}$ is associated with an inadequate availability of insulin and usually manifests in childhood, whereas type $2 \mathrm{DM}$ is related to insulin resistance and usually manifests in adulthood (13). The low incidence of DM-associated mortality in patients with NF1 (0.3\%) seems paradoxical because DM is one of the main risk factors for ASCVD and associated death in the general population (14).

The Neurofibromatosis Outpatient Reference Center (CRNF) of the Clinics Hospital of the Federal University of Minas Gerais has managed over 800 patients with NF1, among whom there has been no reported case of type 2 $\mathrm{DM}$ and only two cases of type $1 \mathrm{DM}$. Moreover, to our knowledge, there has been no study on the prevalence of DM or increased FBG level in individuals with NF1.

Riccardi, in the first two editions of his book on neurofibromatosis $(15,16)$, to some degree focused on
(C) 2016 The authors Published by Bioscientifica Ltd. body habitus, DM, and FBG. In the 1986 edition, there were several noteworthy observations: i) in 147 patients with NF1, the age- and sex-corrected average weight centile was $45.4 \pm 32.1$ (i.e., there was an inclination toward leanness); and ii) in 233 patients with NF1 (of all ages), FBG level was normal, except for equivocal elevation in seven cases (3\%). In the 1992 edition, they reported having seen very few cases of DM among patients with NF1.

According to the American Diabetes Association (ADA), FBG level is the main criterion used to diagnose DM (17). Therefore, the present study aimed to compare FBG level between adults with NF1 and non-NF1 controls.

\section{Methods}

This retrospective, observational, cross-sectional study was based on medical record review of all patients with NF1 attending CRNF from January 1, 2005, to December 31, 2013. Inclusion criteria were age between 35 and 74 years; recorded data on FBG, sex, weight, and height; and at least three positive diagnostic criteria for NF1 according to the National Institutes of Health guidelines (18). All records with a diagnosis of DM were excluded from analysis. The age cut-off points were chosen to match the non-NF1 controls available from the Longitudinal Study of Adult Health (ELSA) in Brazil.

The newest FBG data in the medical record were used. Patients were instructed to fast for at least $8 \mathrm{~h}$ based on NF1 subject written information, and FBG level was measured using a colorimetric method (VITROS equipment and Ortho-Clinical Diagnostics reagent; Ortho Clinical Diagnostics, Raritan, NJ, USA).

The NF1 group was compared with a non-NF1 control group selected from the ELSA study - a cohort of 15000 active and retired employees from six federal Brazilian research institutions (19). As in the NF1 group, all ELSA participants with a diagnosis of type 1 or type $2 \mathrm{DM}$ were excluded. Three non-NF1 individuals from ELSA were selected to match each NF1 patient (three controls for each case) according to sex, age, and BMI by a person who was blinded to the FBG levels. Similarity was expressed by a distance measure; in this case, we used the Mahalanobis distance. Pairing was performed using the matching package for $\mathrm{R}(20)$.

To stratify FBG level, cut-off points were established according to the ADA guidelines (21) and were designated as normal $(\leq 99 \mathrm{mg} / \mathrm{dl})$ or high $(\geq 100 \mathrm{mg} / \mathrm{dl})$. BMI was calculated by the equation 'weight ( $\mathrm{kg}$ ) divided by height (m) squared,' and was classified according to the World Health Organization scale for adults (22). Stature was 
Table 1 Characteristics of the NF1 and non-NF1 control groups.

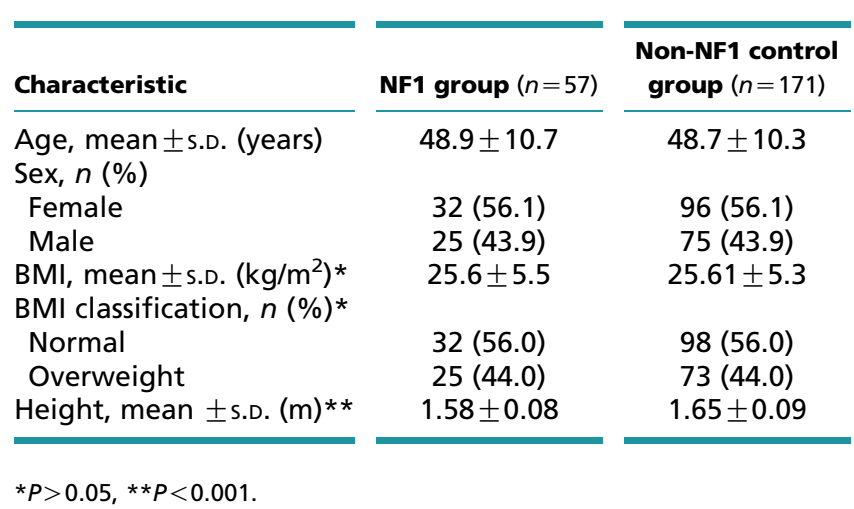

evaluated based on the Centers for Disease Control and Prevention/National Center for Health Statistics parameters for adults (2007-2010) (23). Low height was defined as less than the percentile five.

\section{Ethical aspect}

The Ethics Committee of the Federal University of Minas Gerais approved the present study (No 258.325) and ELSA-Brazil (No 186/06).

\section{Statistical analyses}

Categorical variables included absolute and relative frequencies. The normality of the distribution of variables was tested by using the Kolmogorov-Smirnov test. Normally distributed variables were described as mean \pm s.D., while non-normally distributed variables were described as median, minimum and maximum values. The Wilcoxon signed-rank test was used to compare median FBG level between the two groups, while the McNemar test was used to compare proportions of normal and altered
FBG levels between the two groups. The Mann-Whitney $U$ test was used to compare median FBG level according to BMI and height, while the chi-square test was used to compare proportions of normal and altered FBG levels according to BMI and height. Stepwise multivariate logistic regression was used to evaluate the associations between independent variables and high FBG level $(\geq 100 \mathrm{mg} / \mathrm{dl})$. Covariates with a $P$ value of $\leq 0.25$ in bivariate analysis and biologic plausibility were considered as candidates for the final model. Independent variables were entered into the model one by one in order of decreasing statistical significance, and those that lost this characteristic were excluded. The strength of the association was assessed by calculating the odds ratio (OR) with a CI of $95 \%$. The OR was calculated by using logistic regression to estimate the magnitude of the likelihood of a patient with NF1 having a high FBG level compared with a non-NF1 control, with a CI of 95\%. Statistical significance was established when $P$ was $<0.05$. Analyses were performed using SPSS version 13.0 (SPSS, Inc.).

\section{Results}

We evaluated 701 medical records from CRNF: 175 were excluded because they had less than three diagnostic criteria for NF1 or had other diagnoses (such as neurofibromatosis type 2, Schwannomatosis, or Legius syndrome); two (0.3\%) were excluded due to diagnosis of type $1 \mathrm{DM}$; and 20 were excluded due to absence of exact birth date. Within the 701 records, 504 had at least three diagnostic criteria for NF1, and 184 had data on FBG, weight and height. Of these, 57 patients were aged 35-74 years and were included in this study.

The average age was $48.9 \pm 10.7$ years in the NF1 group and $48.7 \pm 10.3$ years in the non-NF1 control group.

Table 2 Median FBG concentration and prevalence of normal and high FBG concentrations in the NF1 and non-NF1 control groups according to sex.

\begin{tabular}{|c|c|c|c|c|c|c|}
\hline \multirow[b]{2}{*}{ Variable } & \multicolumn{3}{|c|}{ NF1 group } & \multicolumn{3}{|c|}{ Non-NF1 control group } \\
\hline & All $(n=57)$ & Female $(n=32)$ & Male $(n=25)$ & All $(n=171)$ & Female $(n=96)$ & Male $(n=75)$ \\
\hline $\begin{array}{l}\text { FBG level, median } \\
\text { (range), mg/dl }\end{array}$ & $86.0(56-127) *$ & $85.4(76-126) * *$ & $87.0(56-127) * * *$ & $102.0(85-146) *$ & $100.0(85-128) * *$ & $105.0(90-146) * * *$ \\
\hline $\begin{array}{l}\text { Normal FBG } \\
\text { concentration, } n(\%)\end{array}$ & $48(84)^{a}$ & $28(87)^{b}$ & $20(80)^{c}$ & $64(37)^{a}$ & $44(46)^{b}$ & $20(27)^{c}$ \\
\hline $\begin{array}{l}\text { High FBG } \\
\text { concentration, } n(\%)\end{array}$ & $9(16) *$ & $4(13) * *$ & $5(20)$ * & $107(63)^{*}$ & $52(54) * *$ & $55(73) \star \star *$ \\
\hline
\end{tabular}

*NF1 $<$ non-NF1 $(P<0.001)$, **Female NF1 $<$ female non-NF1 $(P<0.001)$, ***Male NF1 $<$ male non-NF1 $(P<0.001)$.

${ }^{a}$ NF1 $>$ non-NF1 $(P<0.001)$.

${ }^{\mathrm{b}}$ Female NF1 $>$ female non-NF1 $(P<0.001)$.

'Male NF1 $>$ male non-NF1 $(P<0.001)$.

http://www.endocrineconnections.org $\quad$ C 2016 The authors
$\begin{array}{ll}\text { DOI: } 10.1530 / E C-15-0102 & \text { Published by Bioscientifica Ltd. }\end{array}$




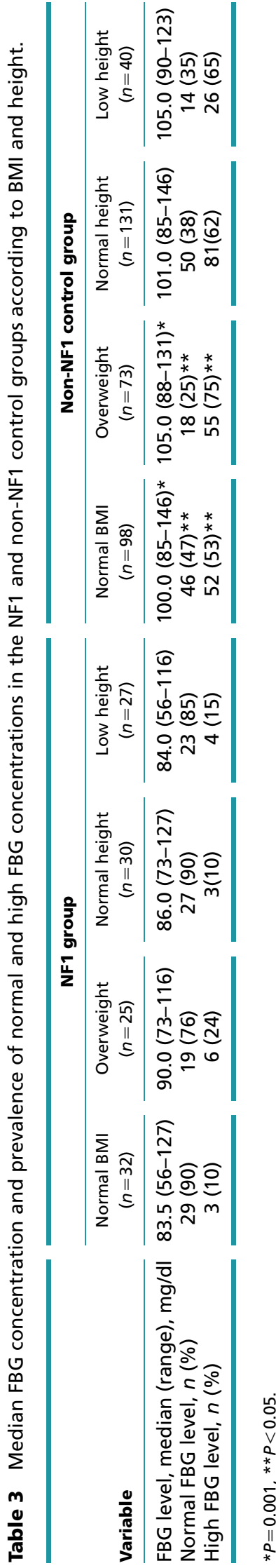

http://www.endocrineconnections.org DOI: 10.1530/EC-15-0102
Women comprised $56.1 \%$ of the participants, and normal BMI was observed in $56 \%$ of both groups. Average height was significantly lower in the NF1 group $(1.58 \pm 0.08 \mathrm{~m})$ than in the non-NF1 control group $(1.65 \pm 0.09 \mathrm{~m})$ $(P<0.001)$ (Table 1).

Median FBG level in the NF1 group ( $86 \mathrm{mg} / \mathrm{dl}$ (range, $56-127 \mathrm{mg} / \mathrm{dl})$ ) was significantly lower than that in the non-NF1 control group (102 mg/dl (range, 5-146 mg/dl)) for both sexes $(P<0.001)$. Prevalence of normal FBG level was significantly higher in the NF1 group $(84 \%)$ than in the non-NF1 control group $(64 \%)(P<0.001)$ (Table 2$)$.

Table 3 shows the median FBG level and prevalence of normal and high FBG levels according to anthropometric measurements in both groups. In the NF1 group, median FBG level was not affected by overweight status $(90 \mathrm{mg} / \mathrm{dl}$ (range, 73-116 mg/dl)) or normal BMI (83.50 mg/dl (range, 56-127 $\mathrm{mg} / \mathrm{dl})$ ). In the non-NF1 control group, median FBG level was significantly higher in overweight individuals (105 mg/dl (range, 88-131 mg/dl)) than in those with a normal BMI (100 mg/dl (range, 85-146 mg/dl)) $(P<0.001)$. In both the NF1 and non-NF1 control groups, median FBG level was not affected by height.

The chance of a high FBG level was 89\% lower in the NF1 group than in the non-NF1 control group (OR, 0.112; 95\% CI, 0.067-0.188). Table 4 shows the final logistic regression model for the factors that influence the FBG levels in the NF1 and non-NF1 control groups. In the NF1 group, age and BMI significantly influenced FBG level. The chance of a patient with NF1 having a high FBG level increased by $5 \%$ for every increase of one year in age and by $12.5 \%$ for every increase of one unit in BMI. In the non-NF1 control group, male patient's sex, age, and BMI significantly influenced FBG level. The chance of a nonNF1 control having a high FBG level increased by 5\% for every increase of one year in age and by $17 \%$ for every increase of one unit in BMI. Men had a 2.3 times greater chance of having a high FBG level compared with women.

\section{Discussion}

In this study, adults with NF1 showed a lower median FBG level and a lower prevalence of high FBG level compared with non-NF1 controls matched by sex, age, and BMI. A literature review found no previous studies assessing the prevalence of abnormal FBG level in patients with NF1 of any age other than the notations by Riccardi cited above. In a recent study, Souza et al. (24) evaluated 60 adults with NF1 and found a similar median FBG level ( $82 \mathrm{mg} / \mathrm{dl})$ in a younger population (mean age, 34 years) than that reported here.

(c) 2016 The authors Published by Bioscientifica Ltd.
This work is licensed under a Creative Commons Attribution-NonCommercial 4.0 International License. 
Table 4 Final logistic regression model for the factors that influence the FBG levels in NF1 and non-NF1 control groups.

\begin{tabular}{|c|c|c|}
\hline & OR $(95 \% \mathrm{Cl})$ & $P$ value \\
\hline \multicolumn{3}{|l|}{ NF1 group } \\
\hline BMI & 1. $12(1.04-1.20)$ & 0.001 \\
\hline Age & 1. 05 (1.01-1.09) & 0.009 \\
\hline \multicolumn{3}{|c|}{ Non-NF1 control group } \\
\hline Male sex & 2. 34 (1.17-4.48) & 0.016 \\
\hline BMI & 1. $17(1.073-1.28)$ & $<0.001$ \\
\hline Age & 1. $05(1.01-1.1)$ & 0.007 \\
\hline
\end{tabular}

In the present study, $44 \%$ of patients with NF1 were overweight, but FBG levels were similar between overweight individuals and those with a normal BMI. Average height of patients with NF1 was significantly lower than that of non-NF1 controls, which has been reported previously $(25,26)$. Nevertheless, median FBG levels were similar regardless of height in both groups.

In logistic regression analysis, BMI influenced FBG level more significantly in the NF1 group than in the non-NF1 control group. In the general population, the relationships between high BMI, age, and impaired FBG level and type $2 \mathrm{DM}$ are well established (27). However, in adults with NF1, the relationship between high BMI and high FBG level has not been established. According to our data, patients with NF1 had a lower chance of having a high FBG level compared with non-NF1 controls. Although data from animal studies have indicated that neurofibromin plays a role in regulating functions of the hypothalamus and pituitary gland (28), which are involved in body energy balance (29), it is unclear whether neurofibromin deficiency could be responsible for the reduced FBG level in individuals with NF1.

A second hypothesis is that adults with NF1 may have higher insulin sensitivity and lower insulin resistance mediated by adipocytokines (leptin, visfatin, resistin, and adiponectin). Adipocytokines are bioactive proteins secreted by adipose tissue $(30,31)$, which influence such physiologic processes as control of food intake, energy homeostasis, angiogenesis, vascular protection, regulation of blood pressure, blood clotting, and insulin sensitivity (30). Several studies have shown the relationships between insulin resistance and type $2 \mathrm{DM}$ and increased plasma concentrations of leptin (32), visfatin (33), and resistin (34), as well as decreased concentration of adiponectin (35). Individuals with NF1 could have lower levels of leptin, resistin, and visfatin, and a higher level of adiponectin, leading to lower insulin resistance, which favors maintenance of lower FBG level and reduced chance of type $2 \mathrm{DM}$.

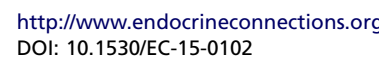

Another hypothesis to explain the lower FBG level in patients with NF1 considers production of insulin-like growth factor 2 (IGF2) by neurofibromas $(3,5)$. IGF2 increases peripheral glucose consumption and decreases glucose production in the liver, leading to hypoglycemia (36). However, further studies are required to verify whether IGF2 produced by neurofibromas could affect FBG level.

The present results suggest the need for further studies to assess glucose metabolism in terms of the glucose tolerance test and 2-h postprandial measurement of serum insulin, glucagon, and glucose.

The sample size could be seen as a limitation of the present study; however, the final number of patients with NF1 (57) is considered high enough for a rare disease study. Finally, another possible limitation of the present study is that the non-NF1 controls were selected from ELSA data without systematic exclusion of conditions, other than DM, that could alter FBG level.

\section{Conclusions}

In conclusion, adults with NF1 showed a lower FBG level and a lower prevalence of high FBG level compared with non-NF1 controls matched by age, sex, and BMI.

\section{Declaration of interest}

The authors declare that there is no conflict of interest that could be perceived as prejudicing the impartiality of the research reported.

\section{Funding}

This study was funded by three Brazilian government funding agencies: CAPES, the National Council of Technological and Scientific Development (number 471725/2013-7) and FAPEMIG (number APQ-00928-11 and number PPM-00120-14)

\section{Acknowledgements}

We would like to thank the researchers of ELSA - Brazil in Minas Gerais for their collaboration and selection of the random sample of controls for this study.

\section{References}

1 Riccardi VM. Neurofibromatosis type 1 is a disorder of dysplasia: the importance of distinguishing features, consequences, and complications. Birth Defects Research Part A: Clinical and Molecular Teratology 201088 9-14. (doi:10.1002/bdra.20616)

2 Radtke HB, Sebold CD, Allison C, Haidle JL \& Schneider G. Neurofibromatosis type 1 in genetic counseling practice: recommendations of the National Society of Genetic Counselors. Journal of Genetic Counseling 200716 387-407. (doi:10.1007/s10897-007-9101-8)

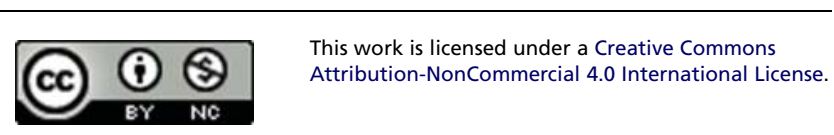


3 Souza JF, Toledo LL, Ferreira MC, Rodrigues LO \& de Rezende NA. Neurofibromatosis type 1: more frequent and severe than usually thought [in Portuguese]. Revista da Associação Médica Brasileira 200955 394-399. (doi:10.1590/S0104-42302009000400012)

4 Pasmant E, Vidaud M, Vidaud D \& Wolkenstein P. Neurofibromatosis type 1: from genotype to phenotype. Journal of Medical Genetics 201249 483-489. (doi:10.1136/jmedgenet-2012-100978)

5 Rodrigues LO, Batista PB, Goloni-Bertollo EM, de Souza-Costa D, Eliam L, Eliam M, Cunha KS, Darrigo-Junior LG, Ferraz-Filho JR, Geller M et al. Neurofibromatoses: part 1 - diagnosis and differential diagnosis. Arquivos de Neuro-Psiquiatria 201472 241-250. (doi:10.1590/ 0004-282X20130241)

6 Rasmussen SA, Yang Q \& Friedman JM. Mortality in neurofibromatosis 1: an analysis using US death certificates. American Journal of Human Genetics 200168 1110-1118. (doi:10.1086/320121)

7 Zöller M, Rembeck B, Akesson HO \& Angervall L. Life expectancy, mortality and prognostic factors in neurofibromatosis type 1 . A twelve-year follow-up of an epidemiological study in Göteborg, Sweden. Acta Dermato-Venereologica 199575 136-140.

8 Masocco M, Kodra Y, Vichi M, Conti S, Kanieff M, Pace M, Frova L \& Taruscio D. Mortality associated with neurofibromatosis type 1: a study based on Italian death certificates (1995-2006). Orphanet Journal of Rare Diseases 20116 11. (doi:10.1186/1750-1172-6-11)

9 Madubata CC, Olsen MA, Stwalley DL, Gutmann DH \& Johnson KJ. Neurofibromatosis type 1 and chronic neurological conditions in the United States: an administrative claims analysis. Genetics in Medicine 201517 36-42. (doi:10.1038/gim.2014.70)

10 Belfort R \& Oliveira JEP. Mortality from diabetes mellitus and other causes in the city of Rio de Janeiro - differences by sex and age [in Portuguese]. Arquivos Brasileiros de Endocrinologia e Metabologia 2001 45 460-466. (doi:10.1590/S0004-27302001000500009)

11 Rampatige R, Gamage S, Peiris S \& Lopez AD. Assessing the reliability of causes of death reported by the Vital Registration System in Sri Lanka: medical records review in Colombo. HIM Journal 201342 20-28.

12 Barell M, Louzada JCA, Monteiro HL \& Amaral SL. Association of cardiovascular disease risk factors and quality of life among health workers [in Portuguese]. Revista Brasileira de Educação Física e Esporte 201024 293-303. (doi:10.1590/S1807-55092010000200012)

13 Selph S, Dana T, Bougatsos C, Blazina I, Patel H \& Chou R. Screening for abnormal glucose and type 2 diabetes mellitus: a systematic review to update the 2008 U.S. Preventive Services Task Force Recommendation. Rockville, MD: Agency for Healthcare Research and Quality Report No. 13-05190-EF-1, 2015.

14 Barreto SM, Passos VM, Almeida SK \& Assis TD. The increase of diabetes mortality burden among Brazilian adults. Revista Panamericana de Salud Pública 200722 239-245.

15 Riccardi VM \& Eichner JE. Neurofibromatosis: Phenotype, Natural History and Pathogenesis Baltimore, MD: Johns Hopkins University Press, 1986.

16 Riccardi VM. Neurofibromatosis: Phenotype, Natural History, and Pathogenesis Baltimore, MD: Johns Hopkins University Press, 1992.

17 American Diabetes Association. Standards of medical care in diabetes. Diabetes Care 201437 5-13. (doi:10.2337/dc13-2369)

18 National Institutes of Health. Neurofibromatosis. NIH Consensus Statement Online 19876 1-19. Available at: (http://consensus.nih.gov/ 1987/1987Neurofibramatosis064html.htm) Accessed July 12, 2015.

19 Aquino EM, Barreto SM, Bensenor IM, Carvalho MS, Chor D, Duncan BB, Lotufo PA, Mill JG, Molina Mdel C, Mota EL et al. Brazilian longitudinal study of adult health (ELSA-Brasil): objectives and design. American Journal of Epidemiology 2012175 315-324. (doi:10.1093/aje/kwr294)
20 Sekhon JJ. Multivariate and propensity score matching software with automated balance optimization: the matching package for R. Journal of Statistical Software 201142 1-52. (available at: http://sekhon.berkeley. edu/papers/MatchingJSS.pdf)

21 American Diabetes Association. Standards of medical care in diabetes. Diabetes Care 201033 S11-S61. (doi:10.2337/dc10-S011)

22 World Health Organization. Physical Status: The Use and Interpretation of Anthropometry Geneva: World Health Organization, 1995.

23 Fryar CD, Gu Q \& Ogden CL. Anthropometric reference data for children and adults: United States, 2007-2010. Vital Health Statistics. Series 11, Data from the National Health Survey 2012252 1-48.

24 Souza ML, Jansen AK, Martins AS, Rodrigues LO \& de Rezende NA. Nutrient intake in neurofibromatosis type 1: a cross-sectional study. Nutrition 201531 858-862. (doi:10.1016/j.nut.2014.12.021)

25 Rodrigues LO, Rodrigues LO, Castro LL, Rezende NA \& Ribeiro AL. Noninvasive endothelial function assessment in patients with neurofibromatosis type 1: a cross-sectional study. BMC Cardiovascular Disorders 201313 18. (doi:10.1186/1471-2261-13-18)

26 Koga M, Koga K, Nakayama J \& Imafuku S. Anthropometric characteristics and comorbidities in Japanese patients with neurofibromatosis type 1: a single institutional case-control study. Journal of Dermatology 201441 885-889. (doi:10.1111/1346-8138.12611)

27 Vazquez G, Duval S, Jacobs DR Jr \& Silventoinen K. Comparison of body mass index, waist circumference, and waist/hip ratio in predicting incident diabetes: a meta-analysis. Epidemiology Reviews 200729 115-128. (doi:10.1093/epirev/mxm008)

28 Hegedus B, Yeh TH, Lee DY, Emnett RJ, Li J \& Gutmann DH. Neurofibromin regulates somatic growth through the hypothalamic-pituitary axis. Human Molecular Genetics 200817 2956-2966. (doi:10.1093/hmg/ddn194)

29 van de Sande-Lee SV \& Velloso LA. Hypothalmic dysfunction in obesity [in Portuguese]. Arquivos Brasileiros de Endocrinologia e Metabologia 2012 56 341-350. (doi:10.1590/S0004-27302012000600001)

30 Guimaraes DED, Sardina FLC, Mizurini DM \& Tavares do Carmo MG. Adipokines: a new view of adipose tissue [in Portuguese]. Revista de Nutrição 200720 549-559. (doi:10.1590/S1415-52732007000500010)

31 Guzik TJ, Mangalat D \& Korbut RJ. Adipocytokines - novel link between inflammation and vascular function? Journal of Physiology and Pharmacology $200657505-528$.

32 Martins MC, Lima FL \& Fonseca A. Relationship between leptin and body mass and metabolic syndrome in an adult population [in Portuguese]. Revista Portuguesa de Cardiologia 201231 711-719. (doi:10.1016/j.repc.2012.08.002)

33 Chang YH, Chang DM, Lin KC, Shin SJ \& Lee YJ. Visfatin in overweight/obesity, type 2 diabetes mellitus, insulin resistance, metabolic syndrome, and cardiovascular diseases: a meta-analysis and systemic review. Diabetes/Metabolism Research and Reviews 201127 515-527. (doi:10.1002/dmrr.1201)

34 Silha JV, Krsek M, Skrha JV, Sucharda P, Nyomba BL \& Murphy LJ Plasma resistin, adiponectin and leptin levels in lean and obese subjects: correlations with insulin resistance. European Journal of Endocrinology 2003149 331-335. (doi:10.1530/eje.0.1490331)

35 Medina-Urrutia A, Posadas-Romero C, Posadas-Sánchez R, JorgeGalarza E, Villarreal-Molina T, González-Salazar Mdel C, Cardoso-Saldaña G, Vargas-Alarcón G, Torres-Tamayo M \& Juárez-Rojas JG. Role of adiponectin and free fatty acids on the association between abdominal visceral fat and insulin resistance. Cardiovascular Diabetology 201514 20. (doi:10.1186/s12933-015-0184-5)

36 Iglesias P \& Díez JJ. Management of endocrine disease: a clinical update on tumor-induced hypoglycemia. European Journal of Endocrinology 2014170 R147-R157. (doi:10.1530/EJE-13-1012)
(C) 2016 The authors Published by Bioscientifica Ltd.
Received in final form 27 November 2015

Accepted 2 December 2015 